Nadine PICAUDOU, L'islam entre religion et idéologie.Essai sur la modernité musulmane

Paris, Gallimard, coll. «NRF essais», 2010, 310 p.

\title{
Sandra Houot
}

\section{CpenEdition} Journals

Édition électronique

URL : http://journals.openedition.org/assr/22514

DOI : $10.4000 /$ assr.22514

ISSN : $1777-5825$

Éditeur

Éditions de l'EHESS

Édition imprimée

Date de publication : 31 décembre 2010

Pagination : 9-242

ISBN : 9782713223013

ISSN : 0335-5985

Référence électronique

Sandra Houot, « Nadine PICAUdou, L'islam entre religion et idéologie.Essai sur la modernité

musulmane », Archives de sciences sociales des religions [En ligne], 152 | octobre-décembre 2010, document 152-94, mis en ligne le 06 mai 2011, consulté le 21 septembre 2020. URL : http:// journals.openedition.org/assr/22514; DOI : https://doi.org/10.4000/assr.22514

Ce document a été généré automatiquement le 21 septembre 2020.

(C) Archives de sciences sociales des religions 


\section{Nadine PICAUDOU, L'islam entre religion et idéologie.Essai sur la modernité musulmane}

Paris, Gallimard, coll. «NRF essais», 2010, 310 p.

Sandra Houot

\section{RÉFÉRENCE}

Nadine PICAUDOU, L'islam entre religion et idéologie.Essai sur la modernité musulmane, Paris, Gallimard, coll. «NRF essais», 2010, 310 p.

1 Plus qu'un livre d'histoire attaché à une aire culturelle distincte, l'ouvrage de Nadine Picaudou, professeure d'histoire contemporaine des sociétés arabes à l'Université de Paris 1, est une réflexion sur le rôle social de l'historien confronté aux représentations et aux généralisations rebattues sur le monde musulman. Le phénomène «islam» et son versant politique, particulièrement, sont le plus souvent mesurés par les lectures contemporaines à l'aune d'une menace et d'un bloc monolithique et figé. L'accroche, en introduction de l'essai, est en l'espèce une adresse critique aux productions scientifiques comme aux ouvrages grand public.

2 Le «moment moderne de l'islam» qui constitue l'objet de réflexion de N.Picaudou débute en 1860 pour s'achever en 1930. Entendu comme un processus, ce «moment» singulier se caractérise par une rationalisation du répertoire religieux et des formes d'engagement social et politique au sein de la sphère musulmane. Si l'ouvrage s'organise formellement autour de trois parties - «dire l'islam», «gouverner par l'islam» et «mobiliser au nom de l'islam» -, le dispositif méthodologique obéit, quant à lui, à un modèle «réticulaire». Fait d'agencements de strates, il a capacité à éclairer le caractère hybride $\mathrm{du}$ «moment moderne de l'islam», en focalisant sur les circulations de sens. 
3 Comme l'indique le sous-titre «Essai sur la modernité musulmane», cet ouvrage se concentre sur un point aveugle: les formes renouvelées d'énonciation de l'islam contemporain. C'est plus précisément au surgissement du «discours moderne» que N.Picaudou porte son attention en empruntant, pour le penser, à la perspective foucaldienne de l'«archéologie» et de l'introduction du discontinu. En s'inscrivant dans le sillage d'«une histoire sociale des idées» (p.16), le projet répond à un double souci: se démarquer, d'une part, d'une démarche linéaire et homogène qui se satisfait d'une succession de faits pour penser un phénomène, à la faveur de l'explication causale. Se déprendre, d'autre part, de la posture essentialiste d'un islam entendu comme un sujet transcendantal, renvoyant à une «fétichisation des origines» (p.12).

4 Il y a là une volonté de dépasser un modèle alternatif renvoyant aux seuls contenus et représentations. La gageure, nonobstant, est de s'attacher aux règles propres à la pratique discursive «qui forment systématiquement les objets dont ils parlent» (Foucault, L'Archéologie du savoir, Paris, Gallimard, 1969, p.67). En l'occurrence, «l'objet historique [islam] qui doit plus aux reformulations modernes du religieux qu'à l'héritage inchangé d'un mode de rapport au divin»(p.30). Symptomatique, le paradigme dual: tradition vs modernité, dont l'usage est extrêmement plébiscité pour aborder les sociétés musulmanes, n'en reste pas moins lié à une représentation dichotomique permanence/innovation.

5 Si elle renvoie implicitement à l'origine, cette opposition fait également courir le risque de confondre «une réalité effective avec des faits de discours» (p.59), à l'instar de la «polarité stagnation/progrès», propre au discours réformiste. Ce type de posture stratégique, qui est adopté par les nouveaux «clercs institutionnalisés» cherchant à s'émanciper d'un islam populaire comme de l'héritage scolastique, s'inscrit également dans un «moment colonial (...) des formes complexes de l'interaction culturelle [qui] constituent une composante interne des redéfinitions de l'islam comme catégorie de pensée et d'action» (p.60). En cela, le développement concernant le thème de «l'intimité»(p.229) ouvre sur des pistes de réflexions fructueuses pour penser la relation à l'autre.

6 L'approche synchronique, qui est privilégiée, a pour fonction de mettre en rapport les configurations qui traversent et nourrissent ce moment moderne des transitions ottomanes (pp.110-162). La synthèse sur les avancées récentes des historiens ottomanistes, au sujet, notamment, de l'ère des Tanzimat et des «transferts de modernité institutionnelle» (p.58), a l'avantage de ne pas écraser le lecteur sous le poids du factuel; elle l'éclaire sur les enjeux complexes qui s'y jouent.

7 Autre apport d'importance est celui d'une mise en lien des espaces géographiques que sont le Machreq et le Maghreb. Ce choix méthodologique rompt avec le schéma discriminateur qui vaut traditionnellement dans la littérature spécialisée. La référence commune de la figure prophétique, modèle de piété et d'engagement dans l'ici et le maintenant, au renouveau confrérique du $\mathrm{XVIII}^{\mathrm{e}}$ des revivalistes de la Sanussiya missionnaire et de l'unitarisme wahhabite, donne la mesure contrastée de deux dynamiques d'émancipation préréformistes (pp.42-49).

8 La mise en rapport d'aires géographiques distinctes aide à l'identification de trajectoires temporellement décalées de mouvements désignés univoquement de «réformistes». Traditionnellement considéré comme l'une des caractéristiques majeures, le lien entre réformisme et nationalisme est, à cet égard, éclairant. Sa survenue, plus tardive au Maghreb qu'en Orient arabe, souligne l'importance à 
accorder aux conditions contextuelles différenciées de productions discursives et de principes d'actions.

Outre les ancrages spatiaux différenciés, ces analyses croisées dessinent des logiques distinctes de politisation que le prisme contextuel, seul, est à même d'éclairer. Attachées à une construction nostalgique au Machreq, qui cherche à penser la transition entre Empire et indépendances, elles sont au Maghreb surdéterminées par l'ordre colonial. L'émergence concomitante de l'association algérienne des Oulémas, pour échapper aux stratégies d'assimilation du colonisateur (p.226), et du mouvement des Frères musulmans égyptiens (pp.239-240) confronté au traité anglo-égyptien, consacrant la dépendance de l'Égypte, est à comprendre en ces termes. «Le moment moderne» voit son surgissement engager, inéluctablement, la structure.

10 La méthode de description des discours modernes, entreprise par N.Picaudou, répond au souci de prendre acte d'une cohérence interne. À la faveur de la variabilité de modes d'énonciation, elle s'attache à ses formes propres, ses enchaînements, autrement dit les glissements, les transformations, voire les ruptures sémantiques. Cette démarche permet de se déprendre de représentations faussées, et pourtant tenues pour évidentes. La proposition avancée, en l'instance, dans le chapitre «Guerre au nom de l'islam» semble des plus pertinentes pour mesurer des «pratiques des jihad» modernes et de leurs usages différenciés, selon les espaces, les acteurs, leurs facteurs mobilisateurs ou leurs tonalités - millénaristes, propagandistes, protestataires -, selon qu'il s'agisse d'une menace intérieure ou extérieure...

11 Plutôt que «de juger de la réalité historique à l'aune d'une norme posée a priori», elle consiste à «inverser la démarche de compréhension: prendre les actes des jihad modernes et être attentif à la pluralité de leurs formes: aux usages qu'ils font de la norme et aux infléchissements qu'ils lui apportent» (p.196). Ce renversement méthodologique donne sens à des pratiques singulières, ancrées historiquement. Bien plus, il s'oppose à une lecture conduite par la seule catégorie du jihad qui rabat ces pratiques sur une abstraction générique.

12 Le constat avéré d'«un écran à l'intelligibilité des choses» (p.196) vaut également pour le temps présent. Le néologisme «jihadisme», construit dans les médias arabes de l'après-11 septembre, puis diffusé par la sociologie politique et repris par des acteurs ultras en quête de légitimité, n'explique rien. Si ce n'est que l'idéologisation est commuée en une norme a priori, en prenant la partie pour le tout, jusqu'à l'absorber. Un traitement similaire est fait à la charia, réduite à «un système coercitif se réclamant de fondements sacrés et dont les prescriptions, strictement codifiées dans un monumental corpus de droit, prétendraient régir tous les registres de l'agir humain, des obligations» (p.93).

13 Les transformations politiques étayées sur les processus d'idéologisation ont déplacé le concept de charia pour le commuer en Loi islamique, critère de la régulation sociale et de sa validité. À la faveur des Tanzimat, dans un passage de l'État musulman à l'État islamique, la charia est incorporée par les Jeunes-Ottomans ou le réformiste égyptien Muhammad Abduh. Elle inaugure, en conséquence, «un constitutionnalisme islamique qui n'est pas sans prolongements contemporains» (p.190), assimilable à une législation d'État.

14 La prise en acte du religieux et de ses modes d'énonciations fait advenir «un nouvel état de choses par la seule vertu de son énonciation» (J.R. Searle. L'Intentionalité, essai de philosophie des états mentaux, Paris, Minuit, 1985, p.207). L'«éthique sociale» (p.170), de 
ce point de vue, est emblématique d'une pratique discursive qui a ses logiques propres. Au concept d'«objectifs de la Loi (maqāsid)», forgé par le juriste andalou du Xve siècle Abu Ishaq al-Shatibi et repris, notamment, par le réformateur syrien Rachid Rida, l'on doit associer le principe fondamental de «bien commun (maslaha)». Prodiguant un complexe dynamique de réflexion éthique, la maslaha est partie prenante de «l'inscription $\mathrm{du}$ religieux dans la sphère sociale». Véritable dérivation anthropologique de la Loi, son truchement, en lien avec les «nécessités», les «besoins», elle a la capacité de concilier le droit islamique avec les enjeux du présent.

La réflexion de Nadine Picaudou vise à dépasser, en les interrogeant via «le moment moderne», des synthèses tenues comme allant de soi. Se départir de la notion d'origine évite le retour, la répétition, pour donner la mesure aux conditions historiques de productions discursives. L'apport le plus précieux de cet essai, selon nous, réside dans la démarche proposée: écouter les dynamiques inhérentes aux «discours islamiques modernes». 